\section{Schlafstörungen durch Kopfschmerzen}

Helga Peter

Marburg, Deutschland

\section{Englischer Begriff}

sleep disorders due to headache

\section{Definition}

Insomnie in Gestalt von Ein- oder Durchschlafstörungen kann bei Kopfschmerzen durch den Schmerz unmittelbar oder durch die Angst vor einer möglichen neuen Attacke entstehen. Es wird in aller Regel von einer psychogenen Ursache der Schlafstörung ausgegangen. $\mathrm{Zu}$ dieser Gruppe von Kopfschmerzen gehört der $>$ „Kopfschmerz vom Spannungstyp“. Ferner verursachen Schmerzen im Bereich des Kopfes wie Trigeminusneuralgie und orofaziale Schmerzen gehäuft Ein- und Durchschlafstörungen.

Zur Übersicht siehe $\triangleright$,Kopfschmerz“. 